will be invaluable in fully understanding fungi as organisms. This is particularly relevant to species which interact parasitically with other organisms or which have the ability to produce complex secondary metabolites, whether suitable for exploitation as pharmaceuticals or agrochemicals or whether hazardous on account of their propensity to act as mycotoxins. Often these functions are closely associated with lipid metabolism, frequently yielding metabolites from a common pool of key intermediates.

In an age when biochemistry is concentrating so much on the molecular level, however exciting, it would appear that metabolic biochemistry is being neglected. This book will be valuable in focusing attention on fungal biochemistry - students, teachers and researchers in the field of microbial biochemistry will do well to consult it. $\square$

P.G. Mantle is a Senior Lecturer in the Department of Biochemistry, Imperial College, University of London.

\section{Academic synergism}

\section{J.B. Butterworth}

Universities in Partnership. By I.C.M. Maxwell. Pp.480. ISBN 0-7073-0270-6. (Scottish Academic Press: 1980.) £15.

Universities in Partnership describes the first 25 years of the work of the InterUniversity Council for Higher Education Overseas, from the time when it was set up by the British universities in 1946 to assist in the creation of new universities in colonial territories which were rapidly becoming independent. Gradually the IUC was called upon to fulfil a wider role in helping these new institutions to develop their academic potential and train their staff. More recently, it became an important vehicle in facilitating better two-way communication between the universities in the UK and some 35 others in developing countries, an important partnership, based in equality, giving benefits to both sides by a number of different forms of relationship of which links between departments have become particularly important.

This record of the universities with which the IUC has had association is impressively comprehensive and portrays their development as seen from the standpoint of the IUC. One is grateful to the author, $\mathrm{Mr}$ Maxwell, for his immense work of distilling the records of the IUC and, from a voluminous amount of material, producing such a readable and full account. At a time when the IUC is becoming the IUPC and merging with the British Council, it is important that all of this material should be available within the covers of one volume.

The book is divided into three parts, the first of which is particularly interesting in that it gives a short and attractive account of the basic theories upon which the work of the IUC has been based, and of the way in which those theories or principles have changed with time. In Part 2, "The Foundation and Growth of the Universities", Mr Maxwell presents the universities in considerable detail, much of which comes from the archives of the IUC. The book seems to change gear between Part 1 and Part 2, the earlier section dealing in a lively way with the principles and policies which evolved over the 25 years. The second part, no doubt because it is dealing with each individual university and is condensed from the IUC records, does not always say what one might wish to hear. In the development of any institution people are crucial, and the end of the period covered by Mr Maxwell was particularly important because indigenous Vice-Chancellors were taking over from expatriates; one would have liked to know more about those individuals whose influence had been crucial in the development of particular universities.

The book, of course, is intended to be a history of the IUC and not of the individual universities with which it was associated. But too close an adherence to the reports of commissions and the decisions of Senates and Councils may not always reveal the reality which is the university. Moreover, it would have been interesting if Part 2 or Part 3 on the role of the IUC had explored more fully some of the important themes referred to earlier in the book, especially the historical growth of the concept of a developmental university. The ideas and plans already current in the 1960 s, as the Kericho Conference in 1966 bears evidence, were having and were to have considerable effect upon the new universities in developing countries. A prime example is the concept of an umbrella university such as Malawi, taking within iteself virtually all post-school education. Another is the single university catering for a number of different countries, evolving from the University of the West Indies, to the University of Botswana, Lesotho and Swaziland, and the experience there acquired being applied in the University of the South Pacific. The concept of a developmental university advanced rapidly after 1970 and it might have been advantageous if Mr Maxwell had not stopped abruptly at that date, for a deeper exploration of these themes could have given guidance and illumination to university development both now and in the future.

Nonetheless, we should be grateful to the author for the valuable work of reference he has made available to us. Those who consult it about particular events in the history of any of the universities are unlikely to be disappointed; it is an extensive and objective record.

J.B. Butterworth is Vice-Chancellor of the University of Warwick, was Chairman of the IUC from 1968 to 1977, and becomes Chairman of the IUPC from 1981.

\section{Of bugs and brains}

\section{Howard C. Berg}

$\overline{\text { Bacterial Chemotaxis As a Model Be- }}$ havioral System. By Daniel E. Koshland. Pp. 193. ISBN 0-89004-468-6. (Raven: 1981.) $\$ 19.50$.

BACTERIA, the most primitive free-living organisms, continuously monitor the concentrations of chemicals in their environment, decide whether these concentrations are rising or falling, shift gears in their rotary engines and swim toward regions that they find more favourable. The modern armament of genetics, biochemistry and biophysics has been brought to bear on this remarkable behavioural system, and some of the processes involved are now understood in molecular detail. Professor Koshland surveys this work in terms intended for both the educated layman and the specialist, striving, as he puts it, to bridge the gap between general interest and scientific accuracy. He then moves with some temerity to a discussion of the function and malfunction of the human brain, arguing that the biochemistry of bacterial chemotaxis is relevant to the nervous system of human beings themselves.

This is a provocative book. It speaks with authority about the interactions of ligands with receptors, receptors with signallers, and signallers with enzymes that methylate and demethylate. It describes models for signalling and adaptation that, although incomplete, have led to a number of fruitful biochemical studies. It contains lively speculations on necessity and chance, memory and learning, and even love and hate.

But I have serious reservations. This is a personal account. The book does not adequately treat pioneering work on bacterial motility and chemotaxis done outside Berkeley. Nor does it make any attempt to place in proper historical perspective the idea that the nervous system of higher organisms evolved from reactions that can be found in the most primitive living things, or the hope that a knowledge of the mechanisms of bacterial chemotaxis might contribute to our understanding of neurobiology and psychology. These concepts are not new. Neurobiologists already know that they need to learn more about the biochemistry of the brain. A biochemist of Professor Koshland's experience might have been expected to offer more insights into problems that they might profitably pursue.

I prefer to think of bacteria as objects of fascination in their own right. Indeed they may prove to be more sophisticated than cells of the human brain. Bacteria have been around for billions of years, and individuals in each generation have had to survive on their own merits.

Howard C. Berg is Professor of Biology at the California Institute of Technology, Pasadena. 